\title{
Our shared history
}

The reconstruction of the genome of a woman of African ancestry from her European descendants, across eight generations, connects living people to a documented saga, drawing attention to the individuals who participated in historic events at a time when the legal, cultural and ethical implications of individual human rights began to gain currency. It is also a technical achievement that extends the methodologies for understanding our interwoven genomic and social histories.

$\mathrm{H}$ ans Jonatan, the hero of the biography The Man who Stole Himself by Gisli Palsson (Univ. Chicago Press, 2016), was born in St. Croix in 1784 to Emilia Regina-an enslaved African woman-and a European father. He traveled with his mother to Denmark where, at the age of 17 , he volunteered for the Danish navy and fought the 1801 Battle of Copenhagen, facing the British under vice admiral Nelson. Despite his patriotic service and the then illegality of slavery under Danish law, Hans Jonatan had to defend a lawsuit against the woman who claimed to own him as well as his mother under the law of the Caribbean colony. Unfortunately, losing the suit left him only the option to 'steal' himself to Iceland, where he became a free and respected storekeeper and farmer, marrying the Icelander Katrin Antoniusdottir in 1820 and founding a pedigree of 788 descendants.

From 182 of these descendants, Anuradha Jagadeesan and colleagues (https://doi.org/10.1038/s41588-017-0031-6) have reconstructed 38\% of Emilia Regina's haploid genome and inferred the SNP variants therein to be most similar to those of current populations in Benin, Nigeria and Cameroon. This feat was made possible by the historical and genetic evidence that there are no other African ancestors in the pedigree and that, prior to the twentieth century, other African gene flow into Iceland has not been detected. The other striking thing this work brings home is what a small piece of the genome from an ancestor just ten generations ago one truly inherits. We are all connected over time by ever smaller recombined fragments.

As the personal genomic sequence information from the African and European individuals who contributed to this work is subject to their consent agreements and various national laws, researchers wishing to work with this information are asked to contact the authors according to their provided Data Availability statement. In an innovation for the journal, the authors have made the data supporting this work available under a Creative Commons Attribution (CC BY) license as linked open access data. We now offer this publication option with several advantages for future scholarship and data reuse as compared to traditional supplementary information (supplementary figures and tables copyright to the authors). First, derivative works can be made provided the paper is cited. Second, new uses such as data modeling and data integration are expressly encouraged. Finally, all additional display items that support the published paper are collected under a single link and Data Availability statement, but individual tables, figures or notes are referenced only where needed to support specific claims in the work. This practice encourages more semantic precision than a requirement to cite all supplementary items regardless of their role in the article's arguments.

From the journal's point of view, public sharing of genetic and family history information-including full personal genomic information-is a public good transmitting knowledge of benefit to the whole human population. That benefit extends beyond the obvious genetic goals of understanding our evolution and disease susceptibilities. The more we know of our common origins, histories of admixture and global population movements, the more we help one another to absorb our commonality and differences. These goals are outside genetics, in anthropology and history, and in society. Perhaps the implications of our shared genome will be identified by individuals who are scholars in only a part of their lives. To enable their investigations, we need to engage the curiosity of individuals to find a personal interest and to further their own story. And for that we need to publish in ways that allow individuals to take and explore their own combinations of our shared heritage of genomic information.

Published online: 26 January 2018 https://doi.org/10.1038/s41588-018-0049-4 